KULTUROWE

STUDIA

KRAJOBRAZOWE

\title{
Rok wędrującego życia [A Year of a Wandering Life], 2017-2019*
}

Sławomir Brzoska

\section{Photo. 1}

Salar de Uyuni, Bolivia.

\footnotetext{
* S. Brzoska, Rok wędrującego życia, Uniwersytet Artystyczny, Poznań 2017-2019; see B. Frydryczak’s review of Brzoska’s
} book in the present volume. 


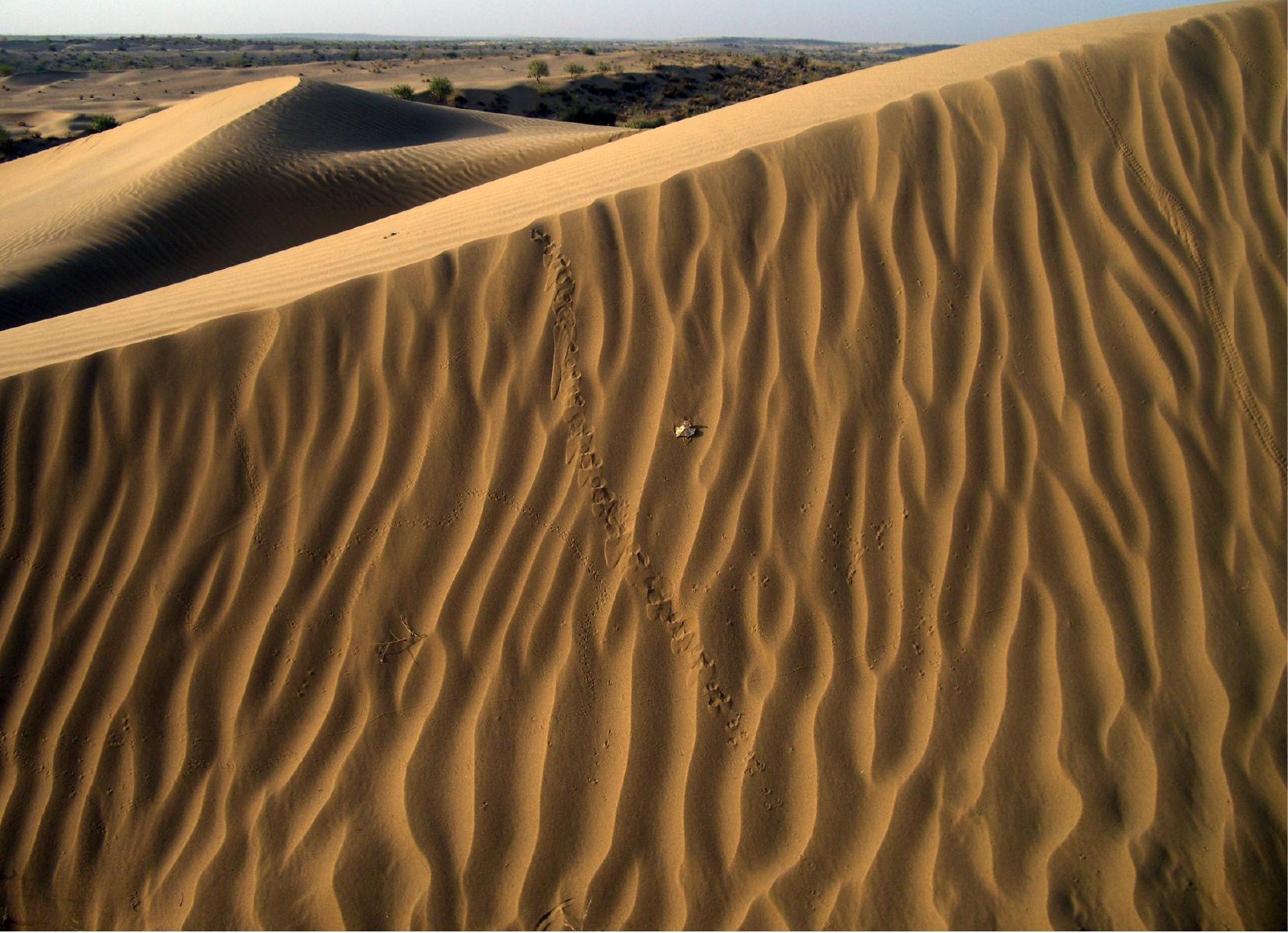

Photo. 2

The Thar Desert, India. 


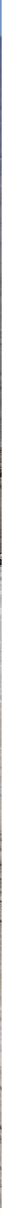

Photo. 3

Negev, Israel. 


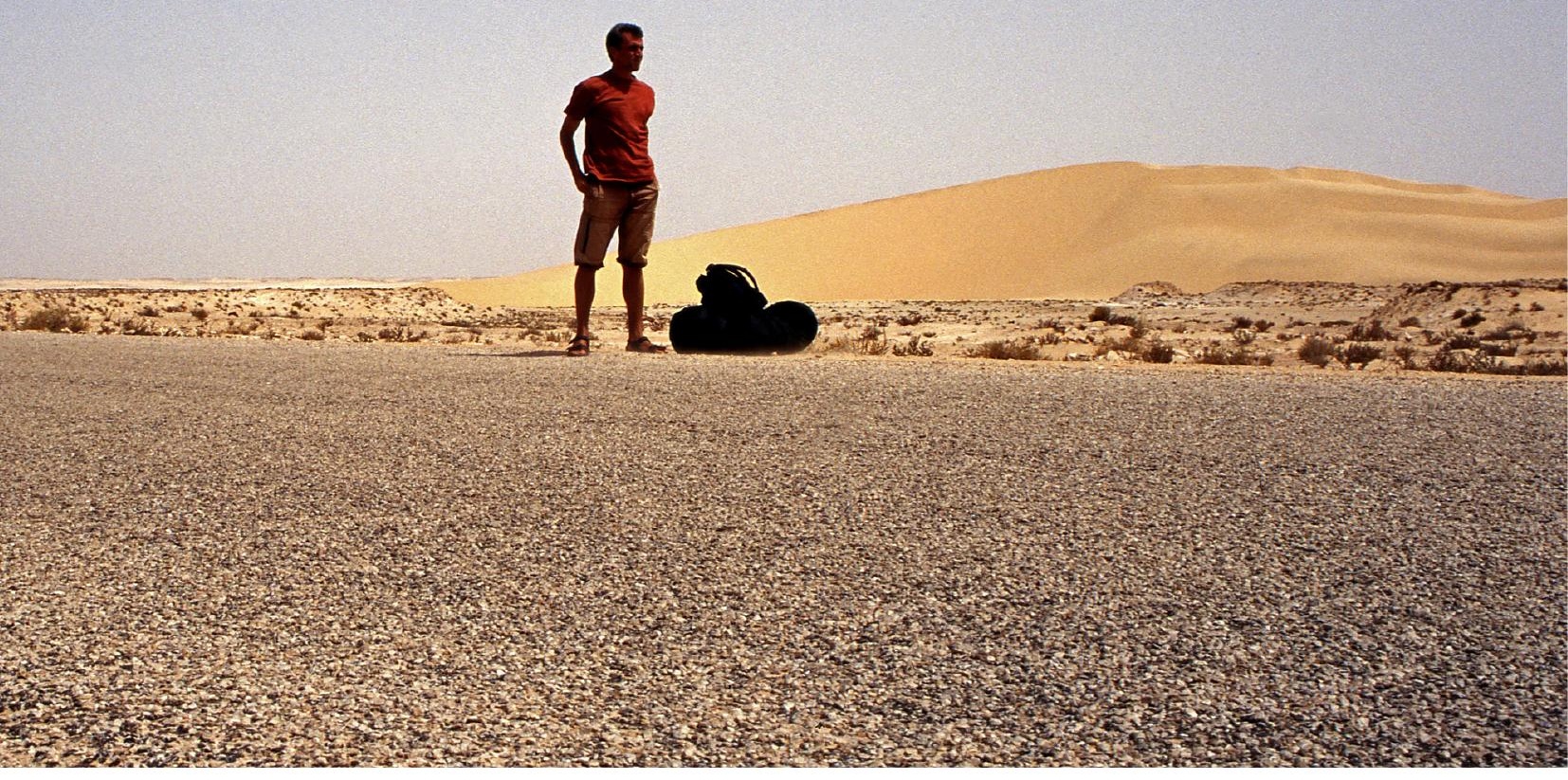

Photo. 4

A Road, Mauritania. 


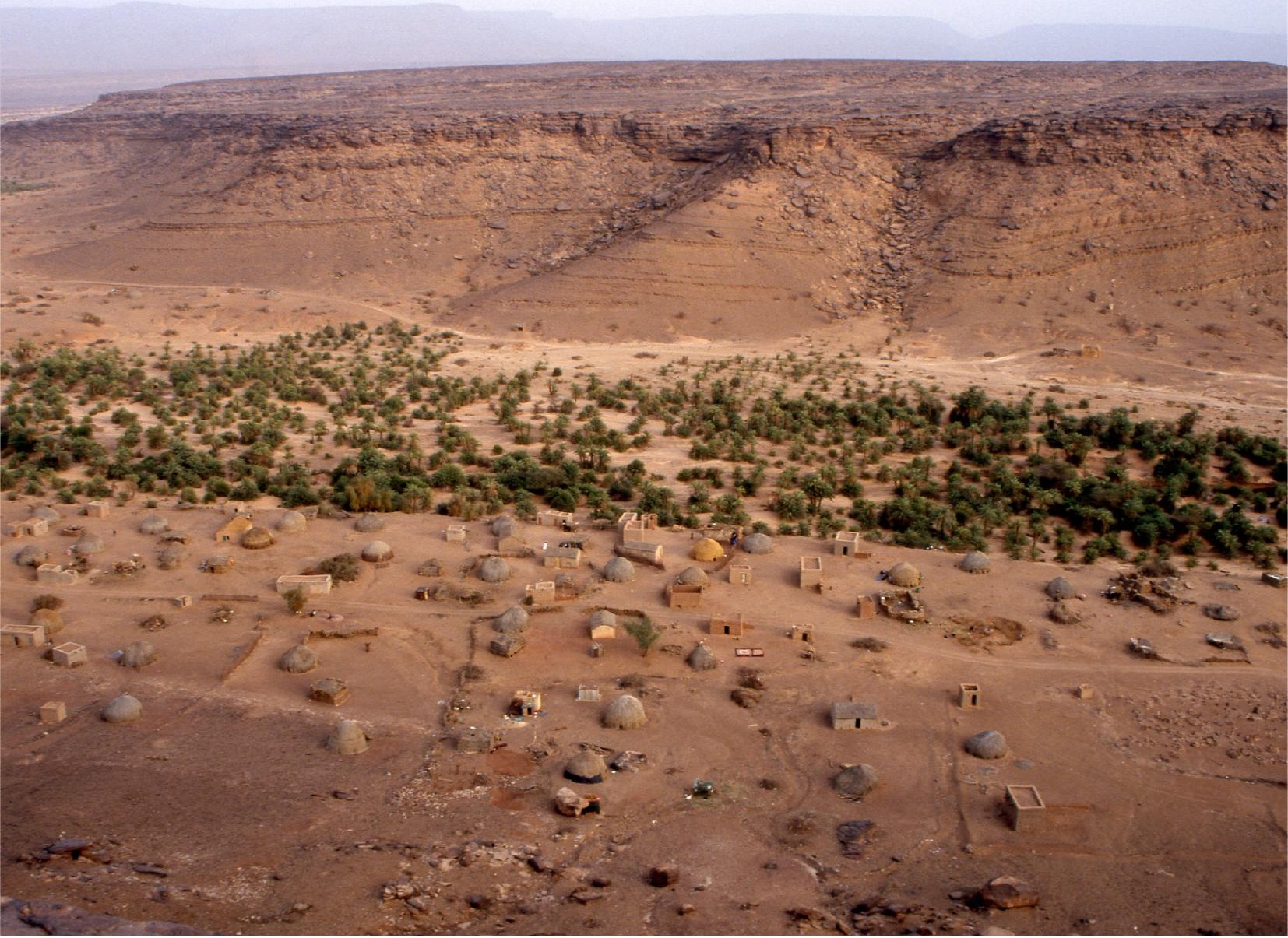

Photo. 5

Teizent Oasis, Mauritania. 


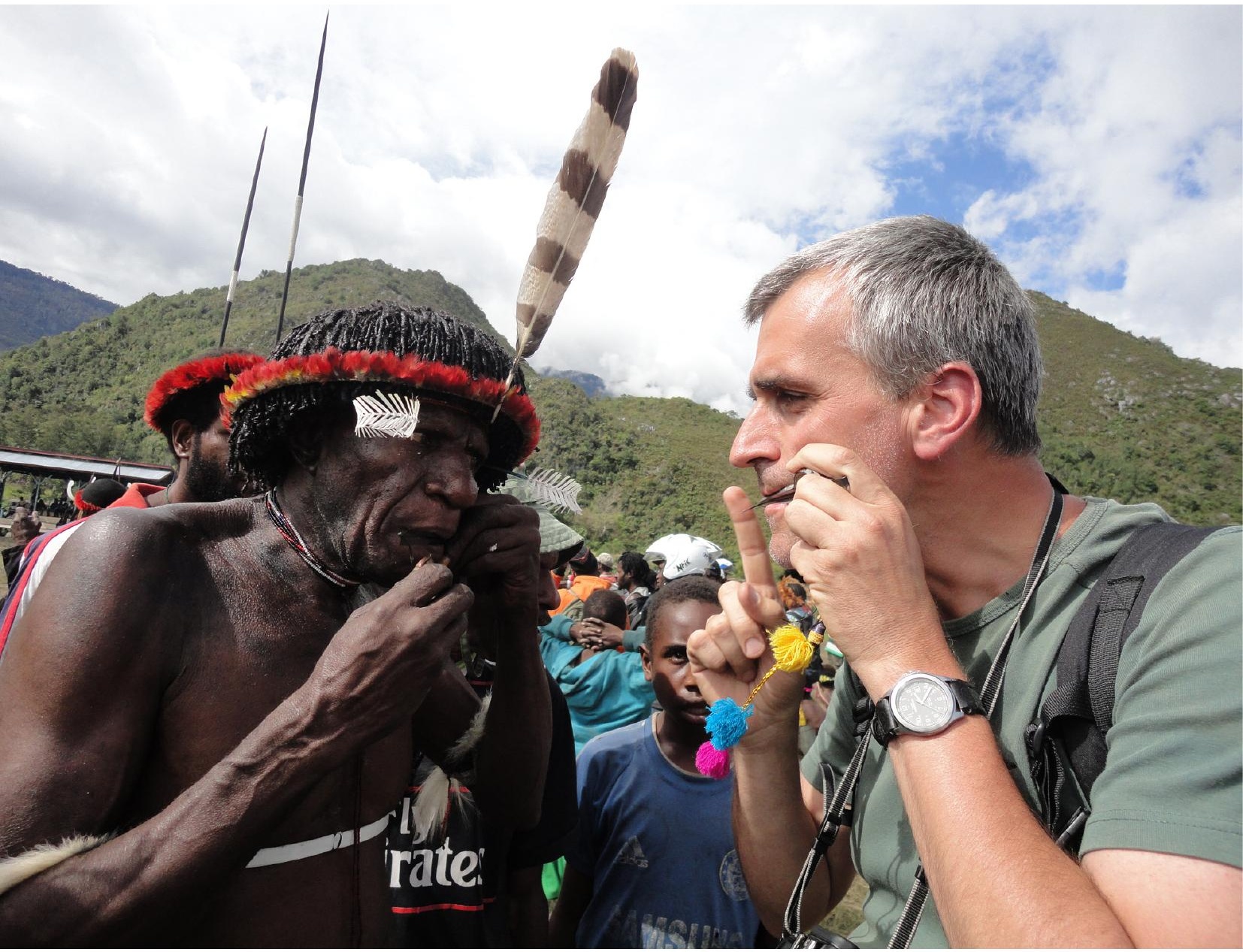

Photo. 6

West Papua. 


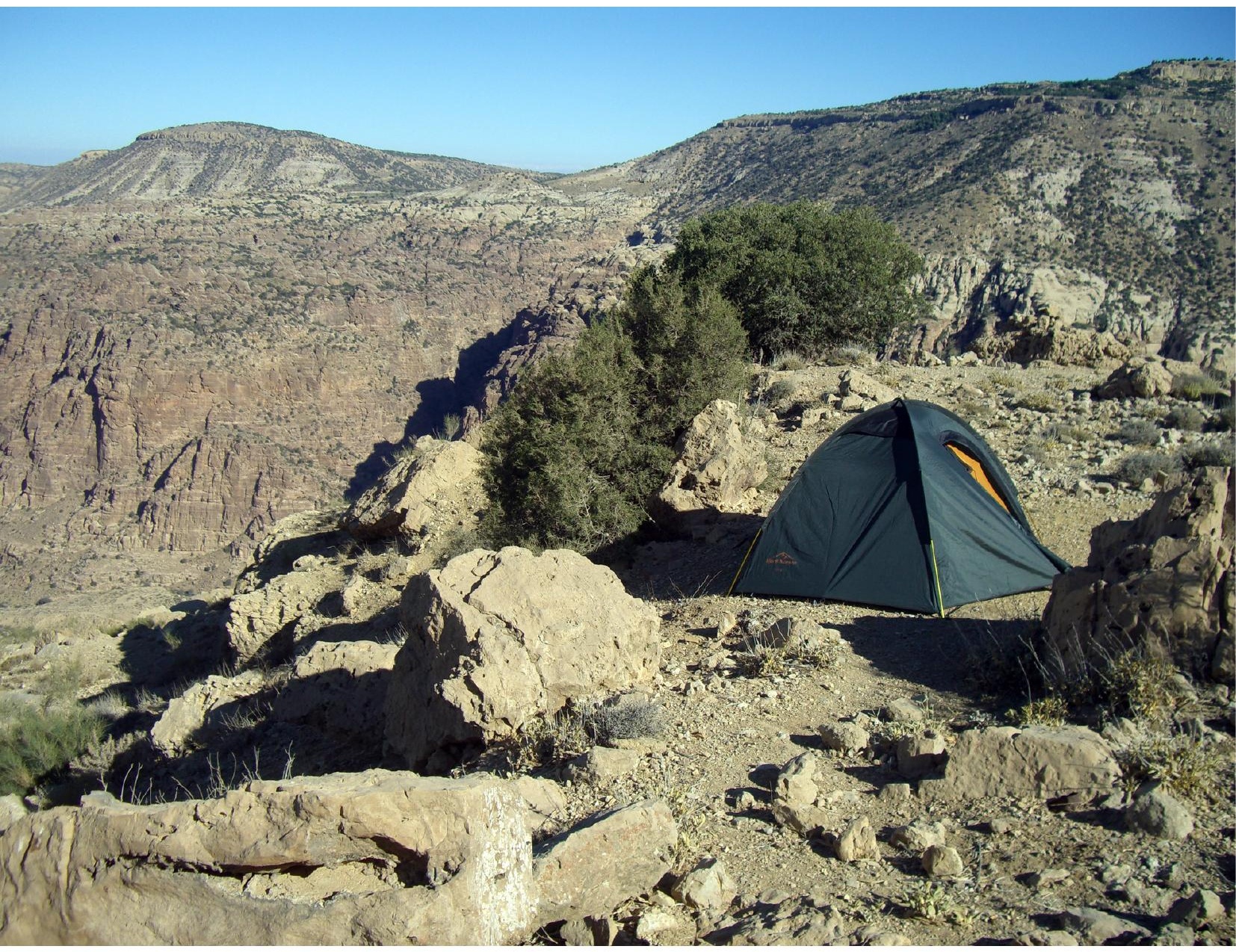

Photo. 7

Syria. 


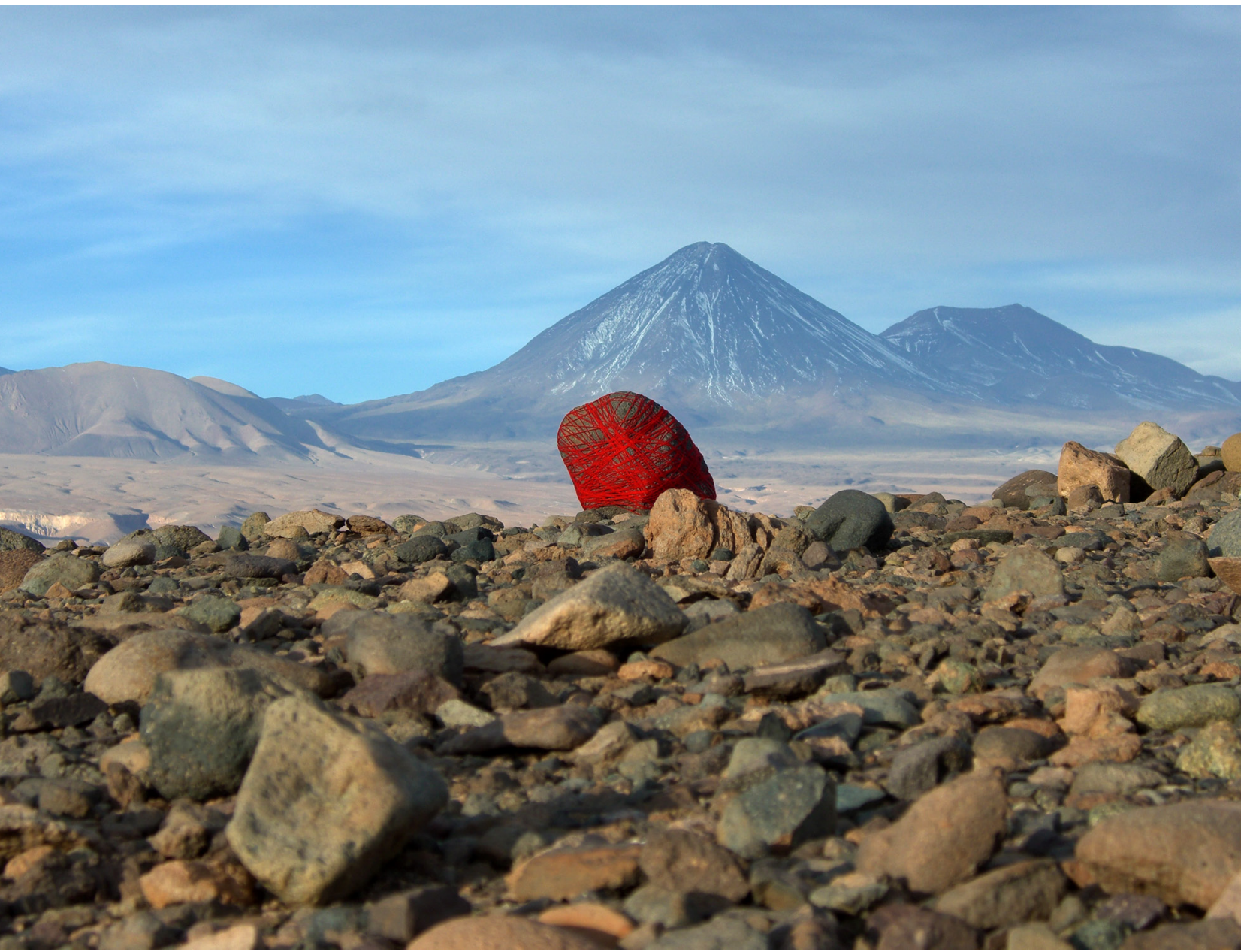

Photo. 8

A Sketch During the Journey. The Atacama Desert, Chile. 


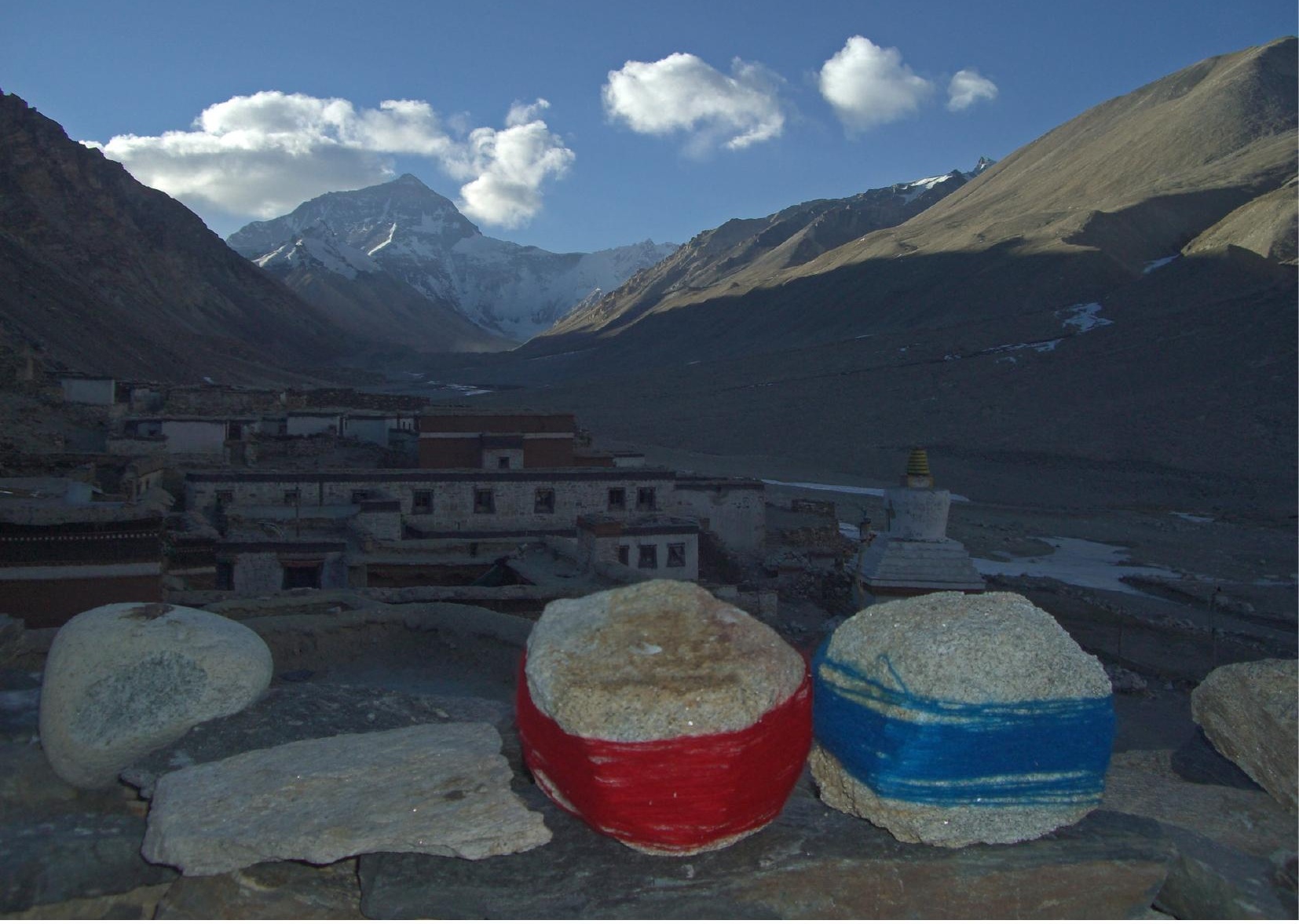

Photo. 9

A Sketch During the Journey. Mount Everest. 


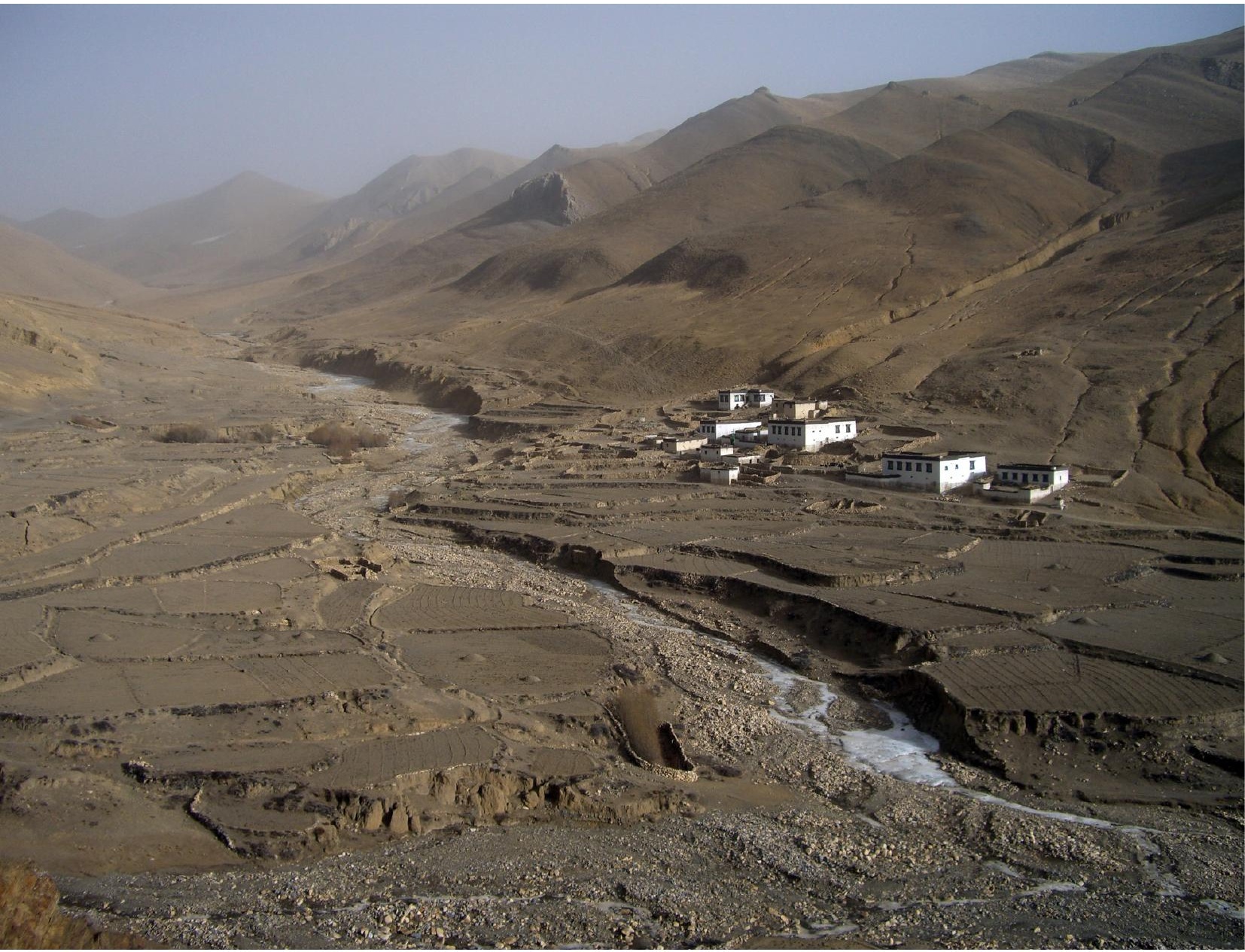

\section{Photo. 8}

Tibet. 